\title{
La experiencia de la náusea y de la obra de arte como evasión: Lévinas y Sartre
}

\section{The Experience of Nausea and Artwork as Escape: Levinas and Sartre}

\author{
Alejandro Macías Flores \\ Universidad Iberoamericana Puebla, México \\ alejandromaciasf@hotmail.com \\ Recibido: 14/01/2016 • Aceptado: 02/02/2017
}

\begin{abstract}
Resumen Abstract
Lévinas and Sartre make a phenom-
enological analysis of the experience of
«nausea» that lead them to the experi-
ence of escaping as a constitutive ele-
ment of the former experience. Escaping
is also constitutive of artwork's function
for both phenomenologists, in the pe-
riod between 1935 to 1945 . I will ar-
gue that the three phenomena -nausea,
escape and artwork- are closely related
according to both philosophers. In first
place, it presents Sartre's proposal on
Literature and Philosophy in relation to
nausea. Then, it punctually reelaborates
Levina's thought on thought, as Sartre's
contemporary, but not as his imitator
and, sometimes, even contrary. Sartre
promoted, back then, Art as a superation
of Philosophy, offered as salvation from
his suggestion of art as social compro-
mise. Levinas thinks of nausea in relation
to shame: nudity either is related to in-
timacy, and then provokes shame, or it
is indifferent to intimacy, but then it is
intimacy that which is object of shame.
For both authors, nevertheless, the

Los análisis fenomenológicos de la experiencia de la «náusea» que realizan Lévinas y Sartre nos llevan a la comprensión del fenómeno de la evasión como elemento constitutivo de dicha experiencia. Asimismo, la evasión también es constituyente de la función de la obra de arte para ambos fenomenólogos entre $1935 \mathrm{y}$ 1945. Trataremos de mostrar cómo estos tres fenómenos (la náusea, la evasión y la obra de arte) están íntimamente relacionadas, según los análisis de ambos filósofos. En primer lugar, se presenta el planteamiento de Sartre, alrededor de su tratamiento filosófico y literario de la náusea. A continuación, se reelabora puntualmente el planteamiento de Lévinas, contemporáneo mas no imitativo del de Sartre y, en algunos casos, aún contrario. Sartre promovió, por aquel periodo, la superación del arte respecto de la filosofía, ofrecido como posibilidad de salvación desde su defensa del arte social e históricamente comprometido. Lévinas, por su parte, conduce a la náusea desde la vergüenza; o bien, la desnudez
\end{abstract}


provoca vergüenza a la intimidad, o bien se vuelve indiferente y, entonces, es la intimidad la que es motivo de vergüenza. Para los dos autores, sin embargo, la vivencia de la náusea, sea que nos ponga en relación con nuestra contingencia o con la existencia como necesidad de la que evadirnos, sea que nos coloque «por encima» o «por debajo» del pensamiento, es la misma desnudez de ser lo que nos muestra: nuestra contingencia. experience of nausea is that of nudity of our own self, our contingency, whether it places us «above» or «under» thought.

Palabras clave: artwork, scape, Lévinas, nausea, Phenomenological analysis, Sartre.

Palabras clave: arte, análisis

fenomenológico, evasión, Lévinas,

náusea, Sartre. 


\section{Introducción}

La obra fenomenológica de Sartre y Lévinas es vasta. Este trabajo no busca agotarla. Se pretenden apuntar, a través de conceptos clave de su pensamiento, las principales diferencias y semejanzas de sus análisis. La adopción del método fenomenológico por ambos pensadores les permitió analizar un espectro de fenómenos que nos brindan un punto de comparación propicio para apreciar las diferencias y similitudes en su adopción del método, así como sus contribuciones a la fenomenología y a la filosofía en general.

Se abordará la vivencia de la «náusea» como punto de partida -y de encuentro-. Tanto Lévinas como Sartre abordan esta vivencia para mostrar su relación con la experiencia del ser. Sin embargo, aunque los escritos donde exponen sus descripciones sobre la náusea son contemporáneos, pues ambos escribieron en los años treinta del siglo XX, no se puede hablar propiamente de una influencia de uno sobre el otro; más bien, por los datos biográficos que se disponen - cartas, testimonios, biografías y entrevistas, entre los más relevantes-, se puede afirmar que dicha influencia no ha sido directa, ${ }^{1}$ sino que caracteriza algo que ambos observaron en el ambiente de la época.

El acto de salir - de evadirse- de la vivencia de la náusea es llevado a cabo a partir del al análisis de la obra de arte. Lévinas hace una crítica a la concepción de obra de arte que Sartre expresa en Lo imaginario, elaborando su propia concepción del arte en el artículo "La realidad y su sombra", que se publicara por primera vez en Les temps modernes (1948) - una revista que, en aquel momento, dirigía Sartre- con una nota preliminar: la redacción de la revista hizo una

1 Jacques Rolland considera que no hay influencia entre Sartre y Lévinas; sin embargo, hace un paralelismo entre ambos filósofos respecto a la náusea, grosso modo asemeja la idea de Lévinas a la descrita por Sartre, y nos señala que hay que entenderla principalmente como Stimmung. (1982: 29 y 79). 
conexión de este texto con las ideas promovidas por su director en Lo imaginario, así como con la concepción, en boga entonces, de la literatura comprometida. Sin embargo, no se trata de una reelaboración sin más de las ideas de Sartre. Ello lo prueba que Lévinas había escrito sobre el problema del arte en ocasiones anteriores, como haría también luego de publicar "La realidad y su sombra". Hay que tener en cuenta De la existencia al existente, publicado en 1947, y "La trascendencia de las palabras”, también publicado por primera vez en Les temps modernes en 1949. Pero las reflexiones sobre el arte no dejan de aparecer en mayor o menor medida en sus escritos posteriores, como Totalidad e infinito. Para el presente análisis, nos concentraremos en su artículo "La realidad y su sombra" porque las reflexiones sobre el arte son tratadas como tema central. Asimismo, se puede encontrar una crítica directa a la concepción sartriana de la obra de arte que se tenía a finales de los años treinta.

La náusea sartriana y la obra de arte como evasión

Sartre comienza a escribir La náusea en 1931. Sin embargo, su obra fue rechazada varias veces antes de publicarse en abril de 1938. En esos años, esta obra literaria era considerada un factum sobre la contingencia. Paul Nizan, Simone de Beauvoir y Sartre, daban el nombre de factum -irónicamente- a cualquier obra que estuvieran realizando y que fuera conformada por algún tipo de análisis, con frecuencia agresivo, que pretendiera relacionar literatura y filosofía (Contat, 2003). Así, Sartre buscaba ligar sus ideas filosóficas con sus creaciones literarias para lograr una mejor expresión de la realidad.

En sus inicios, La náusea no tenía ese título. Sartre se refería a ella como Melancholia, particularmente en referencia al grabado de Doré y a todo el significado que la época clásica diera a la melancolía. Gaston Gallimard fue quien sugirió el cambio de título a La náusea. Pero, antes de intitularse así, se llegó a llamar: Factum sur la contingence, Essai sur la solitude d'esprit, Melancholia y Les aventures extraordinaires de 
Antoine Roquentin (Cohen-Solal, 1999: 224). ${ }^{2}$ Sin embargo, el fenómeno que describe en la novela como «náusea» nunca varió; es decir, el fenómeno no fue cambiado de nombre ni de descripción a lo largo de las modificaciones que se sugirieron antes de su publicación, así como el título y el recorte de algunos pasajes que se consideraban populistas, y de otros que iban en contra de las «buenas costumbres» (Contat, 2003). La náusea a la que hace referencia en la novela siempre fue el fenómeno de la «náusea». Esto nos indica que la novela fue concebida no entorno a la «náusea», sino en relación con aquello que la produce: la «contingencia». Las reflexiones de Sartre sobre esta idea comenzaron en 1926, en un curso de Brunschvicg, según señala Aron (1993). Posteriormente las retoma y las expresa en una libreta de ideas (Les carnet Dupuis) que puede datarse a su periodo de profesor en La Havre (1931-1936). Ahí define a la contingencia del siguiente modo: "Entonces una cosa puede ser sin ser por eso necesaria, lo que no quiere decir que otras cosas sean posibles, ni tampoco imposibles, puesto que lo posible es una categoría psicológica, no una modalidad. Eso es a lo que llamaré «contingente»" (CEuvres romanesque. 1982: 1685). La captación de esta contingencia llegaría a ser, para Sartre, el corazón de la experiencia de la náusea. ${ }^{3}$

El ser se devela. Se descubre por medios de acceso inmediato. Entre esos medios, Sartre señala al aburrimiento, al tedio y a la náusea (2006: 14). En El ser y la nada, Sartre remite, para describirla, a su novela (2006: 378). El hecho de que pueda tomarse seriamente una descripción fenomenológica en una obra literaria tiene su sustento

2 Según Huisman (1981: 27), Marcel habría sugerido escribir Sartre un análisis sobre la viscosidad, y éste lo habría hecho (tanto en El ser y la nada como en La náusea). Huisman le atribuye a ese comentario de Marcel que Sartre haya decidido escribir La náusea. Más allá del debate -poco fructífero- de quién llevó a Sartre a dicha novela, aquí se pretende resaltar el ambiente histórico en el que estaban envueltos tanto Sartre como Lévinas. Ambos asistieron a las reuniones filosóficas que se hacían en la casa de Marcel una vez a la semana, aunque Lévinas lo hizo con mayor frecuencia. Por otro lado, el término de náusea podría proceder de la obra de Kierkegaard, La repetición, donde se puede encontrar la frase "El mundo me da náuseas". En 1933, se tuvo una nueva traducción al francés de dicha obra (Galster, Ingrid. 2001).

3 Estos hechos pueden encontrarse ampliamente narrados en la biografía filosófica de Sartre que escribe Thomas R. Flynn (2014: 137-161). 
en el mismo método: si la descripción es apegada a la experiencia, no importa si se da en una obra de ficción o en una filosófica. ${ }^{4}$

Para Sartre, la náusea no es conocimiento, sino conciencia noposicional de la contingencia que soy; es decir, de mí, siendo un cuerpo. En la náusea se da una aprehensión de sí mismo, en tanto existencia de hecho, de una contingencia absoluta (2006: 383). La náusea revela a la conciencia su propio cuerpo. Tanto para Sartre como para Lévinas, la conciencia no deja nunca de ser cuerpo. Esto no debe conducirnos a pensar la náusea como una metáfora obtenida de los malestares fisiológicos, sino como el fundamento de ellos, el fundamento mismo de lo nauseabundo.

Sartre especifica la diferencia del objeto de la náusea y la angustia, aunque no lo detalla tanto como Lévinas: “Así, la toma existencial de nuestra facticidad es la Náusea y la aprehensión existencial de nuestra libertad es la Angustia" (1982: 168). Se trata, por otro lado, de vivencias que no se contraponen, ya que la náusea no contradice a la libertad, sino que muestra una de las condiciones de posibilidad de ésta, pues la náusea se presenta como una evidencia enceguecedora de la existencia, en donde se revela el carácter de «estar de más» (être de trop) y el absurdo -lo que viene a ser la clave, según Sartre, tanto de la existencia como de la náusea, en esta etapa de su pensamiento-. Además, esta experiencia no puede explicarse, sino sólo describirse: es la experiencia de la contingencia siendo lo esencial; de la existencia siendo la gratuidad perfecta.

Durante los años de 1929 a 1940, Sartre consideró al arte como la salida del sentimiento de lo absurdo, de ese «estar de más» que se nos revela en la existencia. Él mismo denominará, en sus Carnets de la drôle de guerre, esta faceta de su pensamiento como su periodo de «moral estética», en donde plantea la salvación a través del arte (1982: 95). ${ }^{5}$ Salvación, entendida no en su sentido cristiano, sino en

4 Conviene aquí recordar la afirmación de Husserl sobre la ficción y la fenomenología: "La ficción constituye el elemento vital de la fenomenología, como de toda ciencia eidética" (1993: 158).

5 Entre varias referencias a esta relación moral-salvación-arte, se puede destacar la siguiente: "Es esta intransigencia, como por otra parte mi teoría de la contingencia, lo que me condujeron a adoptar una moral de la salvación por el arte, [...] oficialmente 
uno estoico: "imprimir en su naturaleza una modificación total que la haga pasar a un estado de plusvalía existencial” (1982: 107). Esta salvación se descubre al final de La náusea cuando aparece de repente a Roquentin la idea de poder dar una justificación a su existencia a través de una obra de arte, al tiempo que está escuchando una canción de jazz, "Some of these days", interpretada por Sophie Tucker y por el compositor Shelton Brooks. Se da cuenta de que él, Roquentin el historiador, no puede hacer música, pero puede hacer libros; es decir, puede hacer literatura. Se le ocurre, entonces, que debe crear un libro de aventuras, una novela. Ya no un libro de Historia, que era en lo que trabajaba, pues advierte que un existente no puede justificar a otro existente. Hacer un libro de Historia es hablar sobre el pasado de algo o de alguien que ha existido efectivamente, lo cual implicaría una documentación, en lugar de una justificación de la existencia. Por otro lado, la obra de arte le permite al artista dar razón de su ser, aunque éste desaparezca, pues su obra permanece tras de haber muerto, ya que trata la existencia por encima de ella. Es decir, considera que la obra de arte da una cierta permanencia en la existencia a su autor, efectiva a través de las personas que piensan en y que valoran al autor del arte. En La náusea se puede apreciar que Sartre hace declarar a su héroe:

Y habría personas que leerían esta novela y dirían: "Es Antoine Roquentin quien la ha escrito, era un tipo pelirrojo que deambulaba por los cafés", y pensarían en mi vida como yo pienso en la de esta negra: como en algo precioso y medio legendario. [...] Entonces, a través de ella [la novela], tal vez yo podría recordar mi vida sin repugnancia (2004: 250). ${ }^{6}$

todo no era sino contingencia y toda vida estaba perdida, sólo era posible crear fuera de sí obras bellas" (Sartre. 1982 : 112).

6 Varios años después de haberse publicado La náusea, Sartre mismo le declara a Simone de Beauvoir, en 1974, que en la época cuando concibió y escribió su novela consideraba que una "obra de arte sobrevive a su época, por consiguiente yo, su autor encarnado en ella, sobreviré a mi época. Detrás de todo estaba la idea de la inmortalidad cristiana; pasaba de la vida mortal a una supervivencia inmortal" (Beauvoir, 2001: 206). 
De ese modo, en estos años del pensamiento de Sartre, la obra de arte se presenta como una salida a la experiencia de la contingencia que nos brinda la náusea, pero entonces se puede preguntar para comprender mejor su apropiación del método fenomenológico: ¿qué concepción tiene de una obra de arte? La respuesta se halla en un texto de la misma época. Se trata de Lo imaginario, uno de los textos más fenomenológicos de Sartre debido al uso explícito del método.

Se podría rescatar la teoría de Sartre acerca del objeto de la experiencia estética -la obra de arte- de su estudio sobre la imaginación; sin embargo, Sartre no estará del todo satisfecho con el último apartado del texto, en donde habla de la obra de arte, porque el editor le pidió que aumentara su estudio con un apartado sobre el arte, por un lado; y por otro, porque su concepción del arte se fue profundizando y matizando conforme se fue desarrollando su pensamiento. Esta obra, sin embargo, fue escrita en el periodo de La náusea. Por eso se podrían hallar en ella claves para entender las razones por las que en ese momento concebía que el arte es un tipo de «evasión» de la náusea, de la contingencia de la existencia.

En aquella época (1929-1940), Sartre consideraba que la obra de arte es un objeto cuando aparece, aunque no lo hace del mismo modo en que la mesa, la taza, o el teléfono, etcétera. Mientras se ponga la atención en el material del cual está hecha, ella no aparece -no se da la experiencia estética- porque «se esconda», sino porque nunca aparece a una conciencia realizante, sólo a una imaginante. Lo que es real en el objeto estético, o en la obra de arte, son las pinceladas, las combinaciones de letras, la piedra esculpida. Lo bello, por su parte, está aislado del universo, no se da a la percepción sensible. En ese sentido se dice que lo real no es bello. "La belleza es un valor que únicamente podría aplicarse a lo imaginario y que conlleva la nihilización del mundo en su estructura esencial” (Sartre, 1940: 372). Lo bello es el conjunto de los objetos irreales. El gozo estético es sólo un modo de aprehender los objetos irreales, y lo hace a partir de su materialidad. Ahí se da el desinterés de la visión estética (Sartre, 1940: 366).

El artista no realiza la imagen mental de su obra. Sólo la objetiva. Lo que hace es llevar a cabo una analogía exterior que podemos $-\mathrm{y}$ 
tenemos que- aprehender para captar la obra de arte. Así, el artista busca manifestar su imagen mental.

Para que una sensación percibida - un color, una forma, etcétera- sea la sensación de una obra de arte, es necesario percibirla en el conjunto sintético de la obra. La clave está en que el objeto estético -obra de arte- es constituido y aprehendido por una conciencia imaginante que lo pone como irreal (Sartre, 1940: 367). Por ejemplo, acerca del arte dramático, Sartre precisa que "[n]o es el personaje quien se realiza en el actor, es el actor quien se irrealiza en su personaje" (1940: 368), volviendo todo el escenario, todo el vestuario, todos sus movimientos, el analogon que remite al personaje que representa, que no es él y que no está presente en carne y hueso.

Sartre pasa lista a las artes para hacer ver que su concepción no se limita a la pintura o al arte dramático. Al respecto de la música, lo irreal queda manifestado en las piezas musicales que son siempre las mismas, aunque varíen sus ejecuciones. Las sinfonías - por ejemplo- no existen en el tiempo, aunque tengan una duración, pues puedo escuchar la misma sinfonía interpretada por varias orquestas. La sinfonía, al ser escuchada, está fuera de lo real. Hay un desinterés por todo lo que está alrededor de la conciencia que aprehende la sinfonía, la cual "se da en persona, pero como ausente, como estando fuera de alcance” (Sartre, 1940: 370). En este caso, la ejecución de la sinfonía no es la sinfonía sino su analogon. Por eso, Sartre considera que la obra de arte está fuera de la existencia, de lo real, por encima de ella.

La atención con la que aquí se reflexiona sobre la obra de arte es más existencial que estética; es decir, se busca saber qué tiene que ser la obra de arte para que nos permita -según Sartre- escapar de la náusea. Por lo tanto, no se agotan todas las posibilidades de la experiencia estética. Como se ha dicho, la náusea es experiencia de la contingencia de la existencia. Uno puede pensar que se libra de ella al pasar a un plano donde la contingencia ya no rige, pero ese plano tendría que estar por encima de la existencia. Entonces, el objeto de arte se manifiesta como un objeto irreal que se expresa en una falta definida a la percepción sensible. No se da sólo desde un punto de vista, como la percepción, sino que se da por completo -lo que no 
quiere decir que sea perfecto-. Podría decirse que son presentados desde varios puntos de vista a la vez; "son «presentificados» bajo un aspecto totalitario" (Sartre, 1940: 240).

Aquí, el paradigma es el objeto de la percepción, mientras que en la conciencia imaginante, el objeto es irreal pues nunca se alcanza como se hace en la percepción; es decir: no me dará nada nuevo de sí mismo una vez que lo presentifique. Sólo puedo volver presente a la conciencia las características que ya he aprehendido del objeto; en cambio, los objetos de la percepción siempre tienen la posibilidad de presentarme algo nuevo sobre ellos, un nuevo lado, un nuevo tono, etcétera. "Poner una imagen - que en Sartre es esencialmente un objeto irreal- es constituir un objeto al margen de la totalidad de lo real. Entonces, es tener lo real a distancia, franquearlo, en una palabra negarlo" (Sartre, 1940: 352). La imagen es la negación del «mundo», pero de un sólo punto de vista: de ese punto a partir del cual se presentifica el objeto en imagen. La condición esencial de una conciencia imaginante es que ella esté-en-el-mundo, precisamente para que tenga algo que negar y entonces producir las imágenes.

La obra de arte es un escape porque se da o se revela en la irrealidad. Así huimos de la contingencia de la existencia. ${ }^{7}$ "Los valores del Bien suponen el estar-en-el-mundo, ellos apuntan las conductas en lo real y en primer lugar están sometidos a la absurdidad esencial de la existencia" (Sartre, 1940: 372). Pero como se ha dicho, lo bello -lo propio de la obra de arte- es estar "por encima de la existencia”, lo que les da una cierta durabilidad no sujeta al tiempo de la existencia que de otra manera no podría encontrar. Por eso, según Sartre, podemos seguir acercándonos a las obras de la literatura de Cervantes, Shakespeare, Dante o Dostoievski como si hubieran sido escritas ayer (Beauvoir, 2001: 208). Para realzar más la pertenencia de lo bello al ámbito de la irrealidad, Sartre menciona el caso de la belleza de una mujer y el deseo hacia ella. Al contemplar la belleza de la dama, el deseo por ella desaparece, ya que el deseo se realiza en la existencia, en lo que tiene de contingente y absurda (Sartre, 1940: 373), y una vez que está en ella, se olvida de la belleza para

7 Otra huida de la contingencia se puede hallar a veces en las emociones. (Sartre, 1995: 83) 
concentrarse en la satisfacción del deseo. Pero que la belleza pertenezca exclusivamente a la irrealidad no impide que se puedan tener experiencias estéticas a partir de objetos reales que no tengan relación con alguna obra de arte. Así, podemos tener la experiencia estética al ver un atardecer en lo alto de una montaña, cuando la percepción de dicho atardecer se vuelve el analogon de sí mismo que apunta al objeto-irreal-atardecer. Sin embargo, lo irreal, y por lo tanto también la obra de arte, depende del «estar-en-el-mundo» de la conciencia; es decir, de la realidad, pues sólo «nihilizándola» es como pueden aparecer.

La náusea levinasiana y la obra de arte como sombra de la realidad

En la búsqueda de una nueva vía de acceso al ser, Lévinas plantea en De la evasión un análisis de la necesidad de evasión que se manifiesta en nuestro ser. En dicho análisis, comienza a utilizar el método fenomenológico dándole un uso propositivo; a partir de aquí se distancia del comentario crítico a Husserl -y Heidegger- para centrarse en su propia manera de entender el método y el ser mismo. Esa apropiación no impide que manifieste críticas a la concepción heideggeriana del ser. A reserva de un largo proceso de maduración, ya se comienza a ver en esta temprana obra - publicada por vez primera en 1935- los temas que Lévinas desarrollaría más tarde. Aquí encontramos una fenomenología del placer, la vergüenza y la náusea, para descubrir la relevancia del fenómeno de la evasión.

Este análisis de la náusea no deja de remitir a la necesidad de evasión; la náusea es un fenómeno que Lévinas trata de aclarar para mostrar de qué manera nos remite a la evasión. Para aprehender el fenómeno que describe Lévinas es necesario mostrar sus conexiones de sentido con la necesidad, el placer y la vergüenza, al menos sumariamente.

Para la «necesidad de evasión», el ser aparece como un aprisionador, del cual hay que escapar. Aquí, la necesidad se manifiesta ligada al ser, pero no como «privación de...», sino que nos anuncia la pureza del hecho de ser. En efecto, la necesidad, en primera instancia, nos muestra nuestra aspiración a una satisfacción y, por consiguiente, una 
carencia o una limitación de nuestro ser. Sin embargo, la satisfacción de la necesidad no la destruye, pero sí puede presentar una «decepción», ya que la satisfacción que se alcanza mediante el cumplimiento de la necesidad no se lleva a cabo como se esperaba. La necesidad vuelve a aparecer o, simplemente, hay «un después» en la satisfacción de la necesidad. Aquello puede expresarse como una inadecuación entre la necesidad y su satisfacción. Lo que la necesidad expresa es la presencia de (nuestro) ser y no su deficiencia. En el fondo, se está expresando una plenitud de ser y no una carencia. Lévinas pone énfasis en aquello de lo que se tiene conciencia como siendo requerido para saciar la necesidad, que de alguna manera ya está presente en la conciencia de dicha necesidad: la satisfacción se manifiesta en el placer. De este modo, el placer no aparece como algo estático, sino como algo que siempre se está desarrollando; nunca aparece de súbito para inmediatamente desaparecer. En su desarrollo, el placer se presenta, también, como evasión porque busca romper con las formas del ser. Sin embargo, es una evasión que fracasa pues el placer es «afectividad» y a ésta no se le pueden aplicar las categorías del pensamiento ni de la acción. Una vez que se ha «sentido» el placer de la satisfacción de la necesidad, aquella experiencia nos puede conducir a la vergüenza de nosotros mismos por haber sido complacidos.

En una primera descripción, Lévinas dice que la «vergüenza» es "la representación que nos hacemos de nosotros mismo como de un ser disminuido; sin embargo, uno con el cual nos es penoso identificarnos" (1982: 111). Nos aprehendemos como disminuidos porque unos momentos antes de «sentir» la vergüenza estábamos complacidos por la satisfacción de la necesidad que nos mostraba la plenitud de nuestro ser, con el que nos identificábamos y al cual ahora tenemos que renunciar. El objeto de la vergüenza somos nosotros mismos. ${ }^{8}$ Por eso dice Lévinas que nuestro cuerpo es vergonzoso sólo cuando en él está patente la intimidad de nuestro ser. Cuando

8 Tanto Sartre como Lévinas se dan cuenta de esto, sin embargo, difieren en lo que nos motiva a sentir vergüenza. En su análisis, Sartre descubre al prójimo como esencial para que yo sienta la vergüenza de mi ser. Para Lévinas, en cambio, el prójimo puede formar parte de la experiencia de mi vergüenza; pero en este análisis no lo presenta como algo imprescindible. 
se pierde esa intimidad manifestada, nuestro cuerpo deja de ser vergonzoso. Pero, advierte, "entonces es nuestra intimidad, es decir, nuestra presencia a nosotros mismo lo que es vergonzoso" (Lévinas, 1982: 114). ${ }^{9}$ En la vergüenza se nos manifiesta todo nuestro ser.

Entonces, ¿cómo la vergüenza nos conduce a la náusea? Si bien, es cierto que no siempre que se tiene vergüenza se padece una náusea, se trata de vivencias que pueden implicarse, según Lévinas. Pueden hacerlo porque la náusea se presenta como malestar y como una presencia indignante de nosotros a nosotros mismos, igual que la vergüenza. "El fenómeno de la vergüenza de sí ante sí mismo [...] no hace sino uno con la náusea” (Lévinas, 1982: 117). Para comenzar, la náusea no puede ser entendida desde la fisiología simplemente, y menos cuando se intenta dar un enfoque fenomenológico. El fenómeno que se designa aquí como náusea, es el fundamento de la «náusea fisiológica». En ella se pierde de "vista todo lo que es" y la nada se manifiesta como el ser puro.

En la náusea no hay ningún intermediario entre ella y nosotros mismos; lo que hay es un esfuerzo por salir, un esfuerzo que se convierte en desesperación cuando se hace patente el hecho de estar pegado a sí mismo. Todo nuestro ser se nos hace patente de golpe. Lévinas dirá que ese hecho constituye la angustia de la náusea. Mientras que la angustia y la náusea se caracterizan ambas por la indeterminación de su objeto, se diferencian por el modo en relacionarse con lo indeterminado. La angustia realza la diferencia ontológica, mientras que la náusea va detrás de ella, "por debajo". ${ }^{10}$

9 Es curioso que Lévinas ilustre esta pérdida de vergüenza por la intimidad de la desnudez del cuerpo en el caso de un boxeador o de una bailarina, quienes muestran sus cuerpos al realizar sus actividades deportivas o artísticas, y haga omisión de un acto íntimo en donde hay vergüenza por mostrar el cuerpo desnudo también: el acto sexual consentido. Sin embargo, hay que señalar que la vergüenza aparece si alguien, ajeno al acto de los amantes, los descubre mientras se expresan su amor.

10 Para ahondar en la distinción entre angustia y náusea, en el pensamiento de Lévinas, se puede consultar el estudio introductorio a De l'évasion de Jacques Rolland, "Sortir de l'être par une nouvelle voie", particularmente las páginas 37-44. "La náusea difiere fundamentalmente de la angustia en lo que, detenida en el suspenso donde ella se atrasa, ella se hace pasión del retorno, bajo las especies del "ninguno", del Kein, de nada que ella no haya manifestado" (Rolland en Lévinas, 1982: 38). 
En la náusea, "que es una imposibilidad de ser lo que se es, se está al mismo tiempo pegado a sí mismo, aprisionado en un círculo estrecho que sofoca, [pues ella] es la experiencia misma del ser puro" (Lévinas, 1982: 116). Se trata de una experiencia de la impotencia del ser, de la fuente de necesidad, en la que se nos puede presentar un «no-hay-nada-más-por-hacer» que nos indica una situación límite de la que hay que salir. De ese modo, la experiencia del ser puro es experiencia, también y al mismo tiempo, de evasión, y "la evasión es la necesidad de salir de sí mismo, es decir, de romper el encadenamiento más radical, más irremisible, el hecho de que el yo es sí mismo" (Lévinas, 1982: 98). En la náusea se nos manifiesta la desnudez del ser en plenitud; nuestro ser al mismo tiempo que lo irremisible de su presencia, nos sofoca. La náusea es la afirmación del ser, es ineludible en cuanto experiencia; es desesperación (Lévinas, 1982: 117 y 119).

En "La realidad y su sombra", Lévinas va a desarrollar las ideas que ya ha expresado en obras anteriores - como en De la existencia al existente, en su apartado sobre "El exotismo" y "Existencia sin existente"-. En su artículo, parte del dogma admitido en el arte acerca de la función expresiva de éste: el arte tiene que poder decir lo inefable, poder ir más allá de la percepción vulgar. Su expresión se basa en un concomimiento que le permitiría al arte ponerse más allá de lo real pues con el poema, la pintura, la música, expresa lo que el lenguaje común no puede. La crítica profesional del arte comparte el dogma y, si hay crítica, es porque el espectador no se basta con el goce estético, sino que tiene que hablar(lo); es decir, busca expresar su experiencia estética.

Lévinas propone otra manera de interpretar al arte fuera de esta función expresiva que se le atribuye en su tiempo. Así, señala que la primera característica que hallamos en la obra de arte es la de su «acabamiento»y, por ese acabamiento, el arte permanece suelto, descomprometido (dégagé). Esto, en oposición al compromiso (engagé) que el arte puede -y debe- adquirir, en especial la literatura. ${ }^{11}$ Lévinas explica que, tal vez, el fenómeno que se vive en esos años

11 Aquí Lévinas hace una de varias referencia implícitas a Sartre, quien en ¿Qué es la literatura? (1948) habla de la literatura comprometida (engagée). 
en los cuales el arte se consideraba como dador de conocimiento -el dogma anterior- puede proceder del hecho de abordar la experiencia estética en la literatura donde la materia prima son las palabras, donde el conocimiento se expresa y transmite más fácilmente. En ese sentido, Lévinas defiende la existencia del crítico, pues si el arte originalmente está fuera del mundo, no es ni lenguaje ni conocimiento. Entonces, el trabajo del crítico queda justificado, pues él expresa como conocimiento algo que no hace la obra de arte.

Por el otro lado, la obra de arte se acaba sin importar las interrupciones materiales o sociales. Aunque el acabamiento del arte sea de ese modo, no tiene que conducirnos a la justificación del arte por sí mismo, únicamente, sin nada que lo ligue a la realidad que lo ve nacer: "expresión falsa, en la medida en que sitúa al artista por encima de la realidad y no le reconoce algún maestro; inmoral en la medida en que libera al artista de sus deberes de hombre y le asegura una pretensiosa y fácil nobleza" (Lévinas, 1994: 109). En esta clara-pero no tácita- alusión a Sartre y su moral de salvación por el arte, al situar a éste por encima de la existencia, la crítica no se refiere al sitio del arte, sino a la consideración del arte como superior, de donde se concluye apresuradamente una justificación para no hacer algo por la existencia en la que estamos sumergidos. Más adelante, y concediendo esa posición del arte - no sin que varíe un poco-, Lévinas desprenderá otras conclusiones diferentes a las de la salvación y el desinterés.

Entonces, podemos preguntar de qué naturaleza es este estar «suelto», «descomprometido» (dégagement), por parte del arte. Lévinas lo pondrá como un «por debajo» (en deçà), en vez de un «más allá» (au-delà) de la realidad, pues considera que el ir más allá se realiza con la comprensión, con las ideas, y la función del arte no es comprender. El arte es obscuridad de lo real y ahí reside el tipo de su acabamiento. La obscuridad ${ }^{12}$ del arte no es reductible a categorías

12 Ya en De la existencia al existente Lévinas dice acerca de la obscuridad: “La obscuridad, en tanto que presencia de la ausencia, no es un contenido puramente presente. No se trata de 'algo' que quede, sino de la atmósfera misma de presencia que puede aparecer, ciertamente, inmediatamente después como un contenido, pero que, originalmente, es el acontecimiento impersonal, a-substantivo de la noche y del hay" (2013: 
del conocimiento. Este acontecimiento del obscurecimiento de la realidad se puede describir por medio del arte como un movimiento contrario a la creación religiosa y que, de cierta manera, "consiste en sustituir el objeto con su imagen" (Lévinas, 1994: 110; también 2013: 73), imagen que no es algún tipo de concepto, pues el concepto es el objeto aprehendido, inteligible que ya remite al conocimiento, y la imagen - de la que forma parte la obra de arte-más bien remite a un desinterés. Dicho desinterés se considera una ceguera en relación a los conceptos y una neutralización de la posibilidad de actuar (Lévinas, 1994: 110; también 2013: 74). En este sentido, el desinterés deja a un lado la libertad y, especialmente, su carácter de avasallamiento, al no permitirle comprometerse con algo. Pero “sería más justo hablar de interés que de desinterés, a propósito de la imagen. Ella es interesante, sin ningún espíritu de utilidad, en el sentido de «que convence»" (Lévinas, 1994: 112).

Sin embargo, aquí lo imaginario se presenta también como irreal al ponerse fuera de la realidad y neutralizarla, al ponerla entre paréntesis o entre comillas. La imagen no es un símbolo ni un signo ni una palabra. Se distingue de ellas por el modo en el que se asemeja a su objeto. La semejanza es la relación entre la cosa y su imagen, sin que se esté poniendo algo diferente tanto a la cosa como a la imagen en esa relación.

En esta concepción de la realidad, ella no sólo es lo que es, sino que también es su sombra, su imagen, su doble. Para comprender esto, Lévinas hace referencia a la «alegoría», donde está presente la semejanza «imagen-realidad», ya que ella se presenta como "un comercio ambiguo con la realidad donde ésta no se refiere a ella misma, sino a su reflejo, a su sombra. La alegoría representa, por consecuencia, aquello que en el objeto mismo lo duplica. La imagen, se puede decir, es la alegoría del ser" (Lévinas, 1994: 116).

Otra de las características de la imagen consiste en ser conciencia de la ausencia de un objeto, lo que no neutraliza el acto de poner el objeto, sino que altera su ser. Esto se aprecia a partir de

89-90). Más adelante cobrará mayor relevancia esta presencia de ausencia como una de las características de la imagen. 
la fenomenología del cuadro -modelo que Lévinas considera más adecuado para comprender el arte- y no la de la imagen, pues contemplar una imagen es contemplar un cuadro (Lévinas, 1994: 116). Al contemplar el cuadro, percibimos elementos, tales como la tela, los colores, el marco, etcétera, que nos remiten a la ausencia del objeto que se representa en el cuadro. Eso no quiere decir que dichos elementos materiales nos hacen presente el objeto estético, sino que ellos, a través de su presencia, nos hacen patente la ausencia de dicho objeto.

La imagen tiene un carácter de «ídolo» que manifiesta mejor su particularidad, a diferencia del símbolo y del signo, siendo este carácter lo que nos remite a la irrealidad de la imagen. En efecto, si se dice que la imagen es ídolo, se habla entonces de un tiempo propio determinado de la imagen. Para explicar esto, Lévinas hará un análisis fenomenológico de la estatua: "La estatua realiza la paradoja de un instante que dura sin porvenir. El instante no es realmente su duración" (Lévinas, 1994: 119). De este modo, Lévinas habla de una duración casi-eterna, en donde se le quita al presente su carácter de evanescencia, se queda fijo, pero indicando el porvenir. El instante de la estatua -su «presente sin porvenir»-se manifiesta en relación con la duración y no con la eternidad. La vida de la obra no puede ir más allá del instante, sino que permanece en un entretiempo.

En el instante de la estatua se puede cumplir la simultaneidad de la necesidad y la libertad - que Lévinas llama lo trágico- cuando fija el poder de la libertad en impotencia (Lévinas, 1994: 120-121). Así, la obra de arte manifiesta la caída en el «destino», del tipo que se encuentra en los personajes de novela sumergidos en algo que inevitablemente les va a suceder porque ya está escrito, aunque de alguna manera aún pueden sentir su libertad, haciendo que comulguen, precisamente, tanto la idea de necesidad con la de libertad.

La muerte puede interrumpir la duración del instante al cortarlo; pero cuando el instante dura para siempre, la muerte pierde su poder ante él. Dicho poder se lo arrebata el objeto estético:

El arte cumple precisamente esta duración en el intervalo, en esta esfera que el ser tiene el poder de atravesar, pero donde su 
sombra se inmoviliza. La duración eterna del intervalo donde se inmoviliza la estatua difiere radicalmente de la eternidad del concepto - ella es el entretiempo, jamás terminado, que todavía dura-algo de inhumano y monstruoso (Lévinas, 1994: 124).

De esta forma, el arte introduce en el ser la muerte del instante al cumplir la duración eterna en el entretiempo: "La idea de sombra o de reflejo [...]-de un doblez esencial de la realidad por su imagen, de una ambigüedad «por debajo»- se extiende a la luz misma, al pensamiento, a la vida interior” (Lévinas, 1994: 117). Lévinas considera que hablar de la sombra de la realidad no refiere una metáfora toda vez que se aclare el sentido de ese «por debajo» (en deçà). Uno puede acercarse a la sombra del ser a través de la fisura entre el ser y la esencia. En el arte se prefiere el acabamiento de la sombra de la realidad, en lugar del acabamiento pendiente de ella. Será precisamente en eso que Lévinas señale el desinterés del arte, pero es un desinterés que manifiesta una irresponsabilidad antes que una contemplación estética, pues esta falta de compromiso sólo manifiesta una dimensión de evasión del mundo que ve nacer al arte y que de cierta manera le exige al hombre una respuesta, una acción, un compromiso (Lévinas, 1994: 126). El arte no es comprometido por ser arte simplemente. Por eso, la crítica se vuelve esencial para el arte, ya que no le permite escapar de su responsabilidad, pues lo trata como otro producto humano en dimensiones humanes: técnica, estilo, trabajo, influencias, en resumen, lo trata en sus contingencias.

\section{Conclusión}

Los fenómenos que abordan tanto Sartre como Lévinas tienen puntos de coincidencia más allá de tratar el mismo fenómeno: la náusea, la obra de arte, la vergüenza, la evasión, la imagen. Los análisis que hacen son complementarios al mostrar lo que el otro no muestra, al enfatizar aspectos que el otro deja pasar por alto.

Lévinas considera que la náusea es la experiencia del ser puro, desnudo; Sartre, por su parte, considera que es la experiencia de la 
contingencia de la existencia, de mi existencia. Si bien no describen de la misma manera dicha experiencia, sí tienen la misma intuición: la náusea como experiencia de la existencia pura, de la existencia desnuda que nos provoca una intención de huida, de evasión, porque no se puede soportar el peso de la desnudez de la existencia.

La náusea resulta, también, la experiencia de una conciencia que existe un cuerpo, un cuerpo que bien puede ser cualquiera - grande, gordo, pequeño, débil--, pero que, al final, debe ser uno. Sartre se referirá a eso como la «necesidad de nuestra contingencia». El énfasis que pone Sartre en la náusea está signado por su reflexión sobre la contingencia de nuestra existencia-siempre como cuerpo-, al tiempo que Lévinas coloca el acento en su necesidad. La náusea nos revela así el hecho de una contingencia que no puede dejar de ser contingencia, sólo dejar de ser. Es a través del querer evitar ese hecho de dejar de ser que uno trata de salir de la contingencia para quedarse en la necesidad. Así, el arte comienza a ser parte de estas reflexiones y análisis.

El arte, que los dos pensadores consideran como irrealidad -Sartre por «encima» de la existencia, Lévinas «por debajo»-, nos brinda la «salida» de la contingencia que somos, para instalarnos en la eternidad. El autor de la obra de arte perdura en su creación porque logra atrapar el instante y quedar ligado a él. Tanto Sartre como Lévinas se refieren en este punto a que la conciencia busca la permanencia en el cambio.

Lo que los diferencia es el modo mediante el que aprehenden esa permanencia. Sartre pone el énfasis en la permanencia como acabamiento, como prolongación del hecho de ser, en la irrealidad de la imagen que está desprendida, libre, descomprometida (dégagé) y que, por eso, no muere; mientras tanto, Lévinas enfatiza el otro aspecto: el lado del que partimos huyendo. Se tiene la necesidad de evadirse porque no se soporta la existencia.

Ambos hablan del mismo fenómeno, pero en extremos diferentes. La razón por la que el arte nos brinda la salida perfecta de la fatalidad de la existencia -ya sea como destino (Lévinas) o como contingencia (Sartre) - es que tiene un acabamiento del que la realidad carece y que, además, nunca podrá tener. 
Asimismo, nos encontramos con la misma intuición en ambos análisis acerca del desinterés que caracteriza al arte, que si bien pareciera que apunta en direcciones opuestas, se trata de dos puntos de una misma línea. Tanto Sartre como Lévinas, al hablar de desinterés, hacen referencia a una consideración no utilitaria del objeto artístico: cuando Sartre se refiere al desinterés que hay en la contemplación estética, hace referencia al objeto de la experiencia que se tiene en el arte, no como es considerado en sus remisiones a los útiles, a los cuales tiene alcance -cuando contemplo una estatua no considero los fines para los cuales puede ser utilizada-. El desinterés en el arte, según Sartre, no se refiere a la no-acción como compromiso, sino como uso. ${ }^{13} \mathrm{~A}$ esto mismo se refiere Lévinas cuando habla de interés.

\section{Referencias bibliográficas}

Aron, R. (1993). Mémoires. París: Julliard.

Beauvoir, S. (2001). La ceremonia del adiós. Seguido de Conversaciones con Jean-Paul Sartre agosto-septiembre 1974, J. Carbajosa, trad. Barcelona: Pocket Edhasa.

Cohen-Solal, A. (1999). Sartre 1905-1980. Francia: Gallimard.

Contat, M. (2003). De «Melancholia» à La Nausée. La normalisation NRF de la Contingence. ITEM. Disponible en: http://www.item.ens.fr/index.php?id=27113 [12/04/2017].

Flynn, T. R. (2014). Sartre. A Philosophical Biography. Estados Unidos: Cambridge University Press.

Galster, I, coord. (2001). La naissance du Phénomène Sartre. París: Seul.

Huisman, D. (1981). "Gabriel Marcel lecteur et juge de Jean-Paul Sartre". Presentación del texto L'existence et la liberté humaine chez Jean-Paul Sartre de Gabriel Marcel. París: Vrin.

13 Por eso el paso a la literatura comprometida no será tan brusco en este sentido, pero sí en lo referente a la moral de salvación. La preocupación por la moral en el pensamiento de Sartre siempre estuvo presente, pues sus concepciones literaria y filosóficas apuntaban a una salvación moral o una restitución o una teoría del compromiso. De modo diferente, pero no ajeno, la preocupación por la moral también estuvo presente siempre en el pensamiento de Lévinas. 
Husserl, E. (1993). Ideas relativas a una fenomenología pura y una filosofía fenomenológica, trad. de José Gaos. España: FCE.

Rolland, Jacques. (1982). “De l'évasion: Sortir de l'être par une nouvelle voie”. Montpellier: Fata Morgana.

Lévinas, E. (1982). De l'évasion. Montpellier: Fata Morgana.

Lévinas, E. De l'existence à l'existant. 2013. París: Vrin.

Lévinas, E. (1994). Les Imprévus de l'histoire. París: Fata Morgana.

Lévinas, E. (2006a). Los imprevistos de la historia, T. Checchi, trad. Salamanca: Sígueme.

Lévinas, E. (2006b). De la existencia al existente, P. de Peñalver, trad. Madrid: Arena libros.

Sartre, J.P. (1940). L'imaginaire. Psychologie phénoménologique de l'imagination. France: Gallimard.

Sartre, J. P. (1948). "Qu'est que la littérature?". En Situation II, littérature et engagement. París: Gallimard.

Sartre, J.P. (1982). CEuvres romanesques, M. Contat y M. Rybalka, eds. Colección La Pléiade. París: Gallimard.

Sartre, J.P. (1995). Esquisse d'une théorie des émotions. París: Herman.

Sartre, J. P. 2004. La nausée. Francia: Gallimard Folio

Sartre, J. P. (2005a). Bosquejo de una teoría de las emociones, trad. de Mónica Acheroff. España: Alianza.

Sartre, J.P. (2005b). Lo imaginario. Psicología fenomenológica de la imaginación, trad. Manuel Lamana. Buenos Aires: Editorial Losada.

Sartre, J.P. (2005c). La náusea. México: Época.

Sartre, J.P. (2006a). L'être et le néant. Essai d'ontologie phénoménologique. Paris: Tel Gallimard.

Sartre, JP. (2006b). El ser y la nada. Ensayo de ontología fenomenológica, trad. de Juan Valmar. Buenos Aires: Losada. 